\title{
Szacowanie ryzyka inwestycyjnego udostępnienia i eksploatacji niekonwencjonalnych złóż gazu
}

\begin{abstract}
W artykule zaprezentowano metodę szacowania ryzyka inwestycji udostępnienia i eksploatacji złoża gazu typu shale gas. Jako miarę ryzyka inwestycyjnego przyjęto prawdopodobieństwo przekroczenia, z góry zadanej, maksymalnej rynkowej ceny gazu. Prognozowaną cenę gazu podano w postaci rozkładu prawdopodobieństwa zmiennej losowej zależnej od innych parametrów modelu. Wyniki dla przykładowego zagadnienia prowadzenia inwestycji uzyskano przy użyciu metody Monte Carlo.
\end{abstract}

Słowa kluczowe: niekonwencjonalne złoże gazu, ryzyko inwestycyjne, metoda Monte Carlo.

\section{Estimating the investment risk in unconventional shale gas production}

This paper presents a method of estimation the risk related to shale gas reserves investment. The probability of exceedance of the maximum market natural gas price was assumed as a measure of investment risk. The projected price of gas was given in the form of a probability distribution of the random variable dependent on other parameters of the model. The results, for the sample investment project were obtained by using the Monte Carlo simulation method.

Key words: shale gas production, investment risk, Monte Carlo method.

\section{Wprowadzenie}

Najnowsze wyniki badań związanych z rozpoznaniem struktur geologicznych, kwalifikowanych jako potencjalne lokalizacje tzw. niekonwencjonalnych złóż gazu ziemnego na terenie Polski, wskazują, że ich udostępnienie i eksploatacja związana będzie ze znaczącym ryzykiem inwestycyjnym. Kluczową kwestią dla każdego przedsiębiorcy - pragnącego zainwestować środki finansowe w eksploatację złoża tego typu - będzie ocena opłacalności tego przedsięwzięcia oraz ryzyka zrealizowania inwestycji.

Klasycznym podejściem związanym z oceną ryzyka inwestycyjnego jest analiza strumieni finansowych, służąca do obliczenia oczekiwanej wartości zdyskontowanej netto NPV (Net Present Value). NPV bilansuje urealniane w czasie nakłady inwestycyjne ze zdyskontowanymi przychodami. W takim przypadku miarą ryzyka inwestycyjnego jest wartość oczekiwana ( $E(\mathrm{NPV}))$ i odchylenie standardowe $(\delta(\mathrm{NPV}))[3]$.

Dla potrzeb tego opracowania wybrano autorskie podejście do zdefiniowania miary ryzyka inwestycji jako praw- dopodobieństwa przekroczenia, w zbilansowanym przedsięwzięciu, z góry zadanej maksymalnej jednostkowej ceny gazu osiągniętej w trakcie przebiegu całego procesu związanego z udostępnieniem i eksploatacją złoża gazu typu shale gas. Cena jednostkowa gazu wyznaczana jest w postaci rozkładu prawdopodobieństwa zmiennej losowej. Głównym założeniem do wyliczenia tej wielkości jest zdyskontowanie inwestycji w z góry zadanym okresie czasu. Zaproponowany model wyliczania ryzyka inwestycji jest zgodny, co do zasady, z propozycjami innych autorów [4].

Opracowany model obliczeniowy zastosowano w przypadku udostępnienia i sczerpania jednym odwiertem horyzontalnym strefy drenażu obejmującej strukturę geologiczną przykładowego złoża gazu typu shale gas. Wszystkie dane dotyczące parametrów złożowych są zbieżne z odpowiadającymi im wielkościami publikowanymi przez autorów badających złoża tego typu w Polsce [6]. Uzyskane wyniki zaprezentowano w postaci wyliczonych wartości, tablic i wykresów. 


\section{Stosowane modele wyznaczania ryzyka budowy i rozbudowy PMG}

Wydajność odwiertów horyzontalnych, zlokalizowanych w złożach niekonwencjonalnych, zależy od wielu parametrów. Do najważniejszych z nich można zaliczyć: warunki złożowe przed i po wykonaniu zabiegów intensyfikacyjnych (w tym hydraulicznego szczelinowania), rodzaj i parametry techniczne zabiegów intensyfikacyjnych, techniczne wyposażenie odwiertu oraz długości odcinka horyzontalnego. Największe trudności, związane z obliczeniem „teoretycznej” wydajności odwiertu horyzontalnego (przed jego odwierceniem), powodowane są niedostatecznym rozpoznaniem struktur geologicznych będących przedmiotem udostępnienia i eksploatacji. Obliczenia wydajności wykonane dla złóż tego typu mogą być obarczone dużym błędem.

W literaturze spotkać można wiele różnych metod służących do obliczenia wydajności projektowanych odwiertów horyzontalnych. Wiele z nich opiera się na uwzględnieniu zjawiska desorpcji/resorpcji gazu na powierzchni skały oraz przepływach gazu innych niż opisane prawem Darcy'ego [5]. Na użytek tego opracowania zastosowano metodę opublikowaną przez Mohana Kelkera [2]. Wykorzystuje ona teorię radialnego przepływu gazu do odwiertu pionowego, przy założeniu „efektywnego” promienia odwiertu $\left(r^{\prime}{ }_{w}\right)$. Idea odwiertu pionowego z dopływem gazu z jego strefy drenażu jest w tym przypadku związana $z$ teoretycznym modelem odzwierciedlającym przepływ gazu za pośrednictwem szczelin do poziomego odcinka odwiertu horyzontalnego. Efektywny promień odwiertu to wielkość teoretyczna, dzięki której można obliczyć wydajności odwiertu horyzontalnego z użyciem poniższego wzoru [5]:

$$
r_{w}^{\prime}=\frac{r_{e} \cdot(L / 2)}{a \cdot\left[1+\sqrt{1-[L /(2 \cdot a)] 2} \cdot\left[h /\left(2 \cdot r_{w}\right)\right]^{h / L}\right.}
$$

gdzie:

$$
a=L / 2 \cdot\left[0,5+\sqrt{0,25+\left(2 \cdot r_{e} / L\right)^{4}}\right]^{0,5}
$$

$L$ - długość odcinka horyzontalnego [m], $r_{e}$ - promień drenażu odwiertu [m],

$h$ - miąższość efektywna złoża [m],

$r_{w}$ - rzeczywisty promień odwiertu horyzontalnego [m].

$\mathrm{Z}$ istoty tego modelu wynika, że efektywny promień odwiertu, jako wielkość teoretyczna, uwzględnia obszar drenażu oraz promień rzeczywistego odwiertu horyzontalnego.

Wydajność odwiertu horyzontalnego, przy wyżej sformułowanych założeniach, można obliczyć, sumując wydajność gazu wywodzącego się z matrycy $q_{m}$ z wydajnością gazu pochodzącego ze szczelin $q_{s}$ za pomocą wzorów:

$$
q=q_{m}+q_{s}\left[\mathrm{~m}^{3} / \mathrm{min}\right]
$$

gdzie:

$$
q_{m}=\frac{2 \cdot \pi \cdot k \cdot h}{\mu \cdot z \cdot T \cdot\left(\ln \left(\frac{r_{e}}{r_{w}^{\prime}}\right)-\frac{3}{4}+s\right)} \cdot\left(p_{z}^{2}-p_{r}^{2}\right)
$$

$k$ - przepuszczalność skały złożowej [mD],

$T$ - temperatura złożowa $[\mathrm{K}]$,

$z$ - współczynnik ściśliwości gazu [-],

$s$ - współczynnik skin-effectu [-],

$p_{z}$ - średnie ciśnienie złożowe [MPa],

$p_{r}-$ ciśnienie ruchowe [MPa];

$$
q_{s}=n \frac{2 \cdot \pi \cdot k^{\prime} \cdot h^{\prime}}{\mu \cdot z \cdot T \cdot\left(\ln \left(\frac{r_{e}}{r_{w}^{\prime}}\right)-\frac{3}{4}+s\right)} \cdot\left(p_{z}^{2}-p_{r}^{2}\right)
$$

gdzie:

$$
r_{e}^{\prime}=\frac{L}{2 \cdot n}
$$

$k^{\prime}$ - przepuszczalność efektywna szczelin [mD],

$h^{\prime}$ - zasięg szczelin [m],

$n$ - liczba sekcji szczelinujących [-];

pozostałe oznaczenia - jak wyżej.

\section{Modele wyznaczania ryzyka inwestycji związanej z rozwiercaniem i eksploatacją złoża typu shale gas}

Większość autorów opracowań analizy finansowej ocenia ryzyko inwestycji jako prawdopodobieństwo uzyskania $\mathrm{NPV}=0 \mathrm{w}$ zadanym okresie dyskontowania projektu. Sama wartość NPV - jako różnica pomiędzy zdyskontowanymi przepływami pieniężnymi a nakładami początkowymi - nie niesie żadnej bezpośredniej informacji o podstawowych wielkościach ekonomicznych, takich jak: koszty, ceny jednostkowe, przychody itp., które odpowiadają za wyliczony poziom ryzyka.
W związku z tym zaproponowano metodę, w której miarą ryzyka inwestycji jest prawdopodobieństwo przekroczenia, krytycznej dla rentowności inwestycji, rzeczywistej wielkości ekonomicznej ponad założoną wartość graniczną. Wartością tą jest, w tym przypadku, cena gazu $C_{g, \max }$, za jaką można sprzedać wydobyty w trakcie trwania inwestycji surowiec.

W zaproponowanym modelu założono, że NPV $=0$, i określono, dla jakich wielkości $C_{g}$ równanie to jest spełnione. 
Badaną wielkość wyliczono w postaci rozkładu prawdopodobieństwa zmiennej losowej. Ryzyko inwestycji zdefiniowano jako prawdopodobieństwo przekroczenia z góry zadanej wartości progowej - ceny gazu, na poziomie której zawierane są umowy długoterminowe na rynku europejskim. Zmiennymi losowymi tego modelu są (w obrębie parametrów ekonomicznych): jednostkowy koszt eksploatacji złoża $\left[\mathrm{zł} / \mathrm{m}^{3}\right]$, stopa dyskontowa [-] oraz w grupie parametrów złożowych: przepuszczalność efektywna szczelin [mD], porowatość złoża [-] i średnie początkowe ciśnienie złożowe [MPa]. Opisany wyżej model ma tę przewagę nad bezpośrednim analizowaniem NPV, że wiąże ryzyko z wymierną kosztową wielkością ekonomiczną. Wadą tego modelu jest fakt, że wskaźnik kosztów (w tym przypadku cena gazu) jest tylko wskazówką i nie wiadomo, jaką należy przyjąć wartość graniczną. Można dokonać analizy takiego wskaźnika dla inwestycji na terenie UE, ale trzeba się spodziewać znacznego zróżnicowania w tym zakresie w poszczególnych krajach wspólnoty. Konstruując opisany model, przyjęto następujące założenia:

- inwestycja realizowana jest ze środków własnych firmy (bez kredytu),

- wszystkie zmienne losowe opisane są rozkładami trójkątnymi,

- wszystkie zmienne losowe modelu są, ze swej natury, niezależne.

Podstawowym równaniem modelu jest:

$$
\mathrm{NPV}=0
$$

czyli:

$$
\sum_{t=1}^{n} C F_{t} \frac{1}{(1+k)^{t}}=0
$$

gdzie:

$C F_{t}$ - strumienie pieniężne w kolejnych latach inwestycji, w tym ujemne wartości w pierwszych latach ponoszenia nakładów inwestycyjnych,

$k$ - stopa dyskontowa [-],

$n$ - liczba lat eksploatacji wraz z latami inwestycji;

$$
C F_{t}=Z O N_{t}-N I_{t}-d K O_{t}+A m_{t}
$$

gdzie:

$Z O N_{t}-$ zysk operacyjny netto ze sprzedaży gazu w roku $t$ [tys. zł],
$N I_{t}$ - nakłady inwestycyjne w roku $t$ [tys. zł], $d K O_{t}$ - przyrost kapitału obrotowego w roku $t$ [tys. zł], $A m_{t}$ - odpis amortyzacyjny w roku $t$ [tys. zł];

$$
Z O N_{t}=Q g_{t} \cdot C_{g}-K O_{t}-P O_{t}
$$

gdzie:

$Z O N_{t}$ - zysk operacyjny netto w roku $t$ [tys. zł],

$Q g_{t} \quad$ - wydobycie gazu w roku $t$ [tys. $\mathrm{m}^{3}$ ],

$C_{g} \quad$ - cena gazu [zł/tys. $\mathrm{m}^{3}$ ],

$K O_{t}$ - koszty operacyjne w roku $t$ [tys. zł],

$P O_{t} \quad$ - przyrost kapitału obrotowego w roku $t$ [tys. zł].

Rozwiązując równanie zasadnicze ze względu na $C_{g}$, otrzymujemy:

$$
C_{g}=\frac{\sum_{t=1}^{n}\left(K O_{t}+N I_{t}+d K O_{t}-A m_{t}\right) \frac{1}{(1+k)^{t}}}{\sum_{t=1}^{n} Q g_{t} \cdot \frac{1}{(1+k)^{t}}}
$$

Traktując $C_{g}$ jako funkcję zmiennych podlegających rozkładom losowym, otrzymujemy ostatecznie:

$C_{g}\left(J_{k}, k, k_{s}, f i, p_{z}\right)=\frac{\sum_{t=1}^{n}\left(K O_{t}+N I_{t}+d K O_{t}-A m_{t}\right) \frac{1}{(1+k)^{t}}}{\sum_{t=1}^{n} Q g_{t} \cdot \frac{1}{(1+k)^{t}}}$

gdzie:

$J_{k}$ - jednostkowe koszty eksploatacji [zł/tys. $\left.\mathrm{m}^{3}\right]$,

$k$ - stopa dyskontowa [\%],

$k_{s}$ - przepuszczalność efektywna szczelin [mD],

$f i$ - porowatość skały złożowej [\%],

$p_{z}$ - średnie początkowe ciśnienie złożowe [MPa].

W celu wyznaczenia empirycznego rozkładu prawdopodobieństwa zmiennej losowej $C_{g}$ użyto metody Monte Carlo.

Jako miarę ryzyka inwestycji związanej z udostępnieniem i eksploatacją złoża gazu typu shale gas przyjęto prawdopodobieństwo przekroczenia uzyskanej w trakcie realizacji całej inwestycji ceny sprzedaży gazu $C_{g}$, zadanej granicznej wartości $C_{g, \max }$, i zdefiniowano ją jako funkcję $R$ tej wartości granicznej:

$$
R\left(C_{g, \max }\right)=P\left[C_{g}>C_{g, \max }\right]
$$

\section{Przykład zastosowania metody}

Charakterystyczną cechą eksploatacji niekonwencjonalnych złóż gazu jest to, że każdy odwiert posiada własną strefę drenażu. Oznacza to, że w trakcie eksploatacji zmiany parametrów hydrodynamicznych w strefie drenażu jednego od- wiertu nie wpływają na analogiczne wielkości właściwe dla drugiego odwiertu. W uproszczeniu można założyć, że każdy odwiert sczerpuje swoje „mikrozłoże”. Jeżeli przyjmiemy, że potrafimy oszacować koszty wykonania inwestycji 
w przeliczeniu na jeden odwiert, to możemy uprościć zagadnienie do oszacowania ryzyka inwestycji przy założeniu eksploatacji jednym odwiertem. Przypuszczenie to nie jest do końca prawdziwe, gdyż koszty jednostkowe zależne są od liczby odwiertów (maleją wraz z jej wzrostem) [1]. Dotyczy to kosztów koncesji, budowy infrastruktury, pracy itp. Mimo to dla potrzeb tego opracowania przyjęto uproszczenie polegające na eksploatacji złoża jednym odwiertem. Takie uproszczenie wydaje się być uprawomocnione, zważywszy na fakt, że nie można precyzyjnie oszacować wspomnianych wcześniej kosztów, a zwłaszcza wpływu liczby odwiertów na ich zmianę. Opracowaną metodę przetestowano na przykładowych danych, charakterystycznych dla złóż gazu typu shale gas występujących na terenie Polski. Analizie poddano pięć wariantów zrealizowania i rozliczenia inwestycji:

- wariant zasadniczy A - w którym założono 25-letni okres prowadzenia inwestycji, w tym 23-letni okres eksploatacji,

- wariant B1 - w którym zmniejszono (w stosunku do wariantu A) łączną liczbę lat prowadzenia inwestycji, skracając czas eksploatacji złoża z 23 do 18 lat,

- wariant B2 - w którym zmniejszono (w stosunku do wariantu A) łączną liczbę lat prowadzenia inwestycji, skracając czas eksploatacji złoża z 23 do 13 lat,

- wariant $\mathrm{C} 1-\mathrm{w}$ którym zmniejszono (w stosunku do wariantu A) łączną wartość inwestycji związanej z budową infrastruktury, rozbudową gazociągów i innymi kosztami początkowymi, niezwiązanymi z kosztami wiercenia i intensyfikacji, z 10555 tys. zł do 5250 tys. zł,

- wariant $\mathrm{C} 2$ - w którym zwiększono (w stosunku do wariantu A) łączną wartość inwestycji związanej z budową infrastruktury, rozbudową gazociągów i innymi kosztami początkowymi, niezwiązanymi z kosztami wiercenia i intensyfikacji, z 10555 tys. zł do 15750 tys. zł.

\section{Dane dla wariantu A}

Tablica 1. Parametry złożowe

\begin{tabular}{|l|c|}
\hline \multicolumn{1}{|c|}{ Nazwa parametru } & Wartość \\
\hline Przepuszczalność skały złożowej [mD] & 0,0007 \\
\hline Miąższość efektywna złoża [m] & 200 \\
\hline Temperatura złożowa [K] & 357 \\
\hline Porowatość [-] & 0,03 \\
\hline Promień strefy drenażu [m] & 155 \\
\hline Długość odcinka horyzontalnego [m] & 560 \\
\hline Współczynnik skin-effectu & 0 \\
\hline Zasięg szczelin [m] & 60 \\
\hline Średnica odwiertu [m] & 0,12 \\
\hline Objętość porów [mln m³ $]$ & 1,969 \\
\hline Nasycenie gazem [-] & 0,7 \\
\hline Średnie początkowe ciśnienie złożowe [MPa] & 25 \\
\hline Ciśnienie ruchowe [MPa] & 13,00 \\
\hline Przepuszczalność efektywna szczelin [mD] & 5 \\
\hline Liczba sekcji szczelinujących [sztuk] & 4 \\
\hline
\end{tabular}

Tablica 2. Parametry ekonomiczne

\begin{tabular}{|l|c|}
\hline Rok rozpoczęcia eksploatacji & 3 \\
\hline Okres prowadzenia inwestycji [lata] & 25 \\
\hline Czas ponoszenia nakładów [lata] & 3 \\
\hline Podatek dochodowy [\%] & $19 \%$ \\
\hline Stopa dyskontowa [\%/rok] & $12,5 \%$ \\
\hline Jednostkowy koszt eksploatacji [zł/tys. $\left.\mathrm{m}^{3}\right]$ & 100 \\
\hline Opłata eksploatacyjna [zł/tys. $\left.\mathrm{m}^{3}\right]$ & 5,89 \\
\hline Roczna stopa inflacji [\%] & $2,5 \%$ \\
\hline 1 USD & $3,70 \mathrm{zł}$ \\
\hline
\end{tabular}

Tablica 3. Parametry rozkładów zmiennych losowych modelu

\begin{tabular}{|l|c|c|c|c|}
\hline \multicolumn{1}{|c|}{ Zmienna } & Jednostka & Minimum & $\begin{array}{c}\text { Najbardziej } \\
\text { prawdopodobna }\end{array}$ & Maksimum \\
\hline Jednostkowy koszt eksploatacji & {$\left[\right.$ zł/tys. $\left.\mathrm{m}^{3}\right]$} & 80 & 100 & 120 \\
\hline Stopa dyskontowa & {$[\%]$} & 0,1 & 0,125 & 0,15 \\
\hline Przepuszczalność efektywna szczelin & {$[\mathrm{mD}]$} & 3,5 & 5 & 6,5 \\
\hline Porowatość & {$[-]$} & 0,01 & 0,03 & 0,05 \\
\hline Średnie początkowe ciśnienie złożowe & {$[\mathrm{MPa}]$} & 20 & 25 & 30 \\
\hline
\end{tabular}

\section{Uzyskane wyniki}

W celu oceny uzyskanych wyników należało określić graniczną wartość ceny gazu $C_{g, \max }$, dla której obliczane będzie ryzyko inwestycji. Przyjęto, że graniczna cena gazu jest równa 350 USD/tys. m³ , przy założeniu, że średni kurs USD w ostatnich trzech latach wynosił $3,7 \mathrm{zł}$. Zatem $C_{g, \max }=1295 \mathrm{zł} / \mathrm{tys} . \mathrm{m}^{3}$. Jak już wspomniano, obliczeń dokonano dla pięciu wariantów prowadzonej inwestycji. Uzyskane wyniki zaprezentowano w tablicy 4. 
Tablica 4. Wyniki analizy ryzyka inwestycyjnego

\begin{tabular}{|c|l|c|c|}
\hline \multirow{2}{*}{ Wariant } & \multicolumn{1}{|c|}{ Opis } & $\begin{array}{c}\text { Najbardziej prawdopo- } \\
\text { dobna cena gazu } \\
{[\mathrm{z}]}\end{array}$ & $\begin{array}{c}\text { Wartość ryzyka } \\
\text { wykonania inwestycji } \\
{[\%]}\end{array}$ \\
\hline A & 25 lat prowadzenia inwestycji & 1025 & 18,00 \\
\hline B1 & 20 lat prowadzenia inwestycji & 1027 & 18,20 \\
\hline B2 & 15 lat prowadzenia inwestycji & 1047 & 20,30 \\
\hline C1 & Jak w wariancie A oraz koszty inwestycji pomniejszone o 5305 tys. zł & 955 & 10,70 \\
\hline C2 & Jak w wariancie A oraz koszty inwestycji powiększone o 5305 tys. zł & 1090 & 26,40 \\
\hline
\end{tabular}

Dystrybuantę rozkładu zmiennej losowej ceny gazu - dla wariantu A pokazano na rysun$\mathrm{ku}$ 1, a histogram eksperymentalny dla tego rozkładu na rysunku 2.

Z wykonanych wyliczeń wynika:

1. W przypadku wariantu zasadniczego A wartość wyliczonej funkcji ryzyka jest równa $18 \%$, co oznacza, że prawdopodobieństwo przekroczenia założonej granicznej ceny gazu równej 1295 zł wynosi 0,18\%. Wartością najbardziej prawdopodobną jest cena usługi równa $1025 \mathrm{zł} /$ tys. $\mathrm{m}^{3}$.

2. W przypadku wariantu B1, w którym skrócono czas wydobycia o 5 lat, wartości: wyliczonej funkcji ryzyka i najbardziej prawdopodobnej ceny gazu zwiększyły się nieznacznie: do $18,2 \%$ oraz $1027 \mathrm{zł} /$ tys. $\mathrm{m}^{3}$, co wynika z faktu, że w końcowych latach eksploatacji tempo wydobycia gazu znacznie spada i nie ma to większego wpływu na wyniki ekonomiczne.

3. W przypadku wariantu B2, w którym skrócono czas wydobycia o 10 lat, można zaobserwować znacznie większy efekt zmian badanych parametrów w stosunku do wariantu B1. Obserwowane wartości wyliczonej funkcji ryzyka i najbardziej prawdopodobnej ceny gazu zwiększyły się odpowiednio do: $20,3 \%$ oraz $1047 \mathrm{zl} /$ tys. $\mathrm{m}^{3}$.

4. W przypadku wariantu $\mathrm{C} 1$, w którym zmniejszono nakłady inwestycyjne o 5305 tys. zł, zaobserwowano znaczący spadek wartości: wyliczonej funkcji ryzyka do 10,7\% i najbardziej prawdopodobnej ceny gazu do 995 zł/tys. m³ $^{3}$.

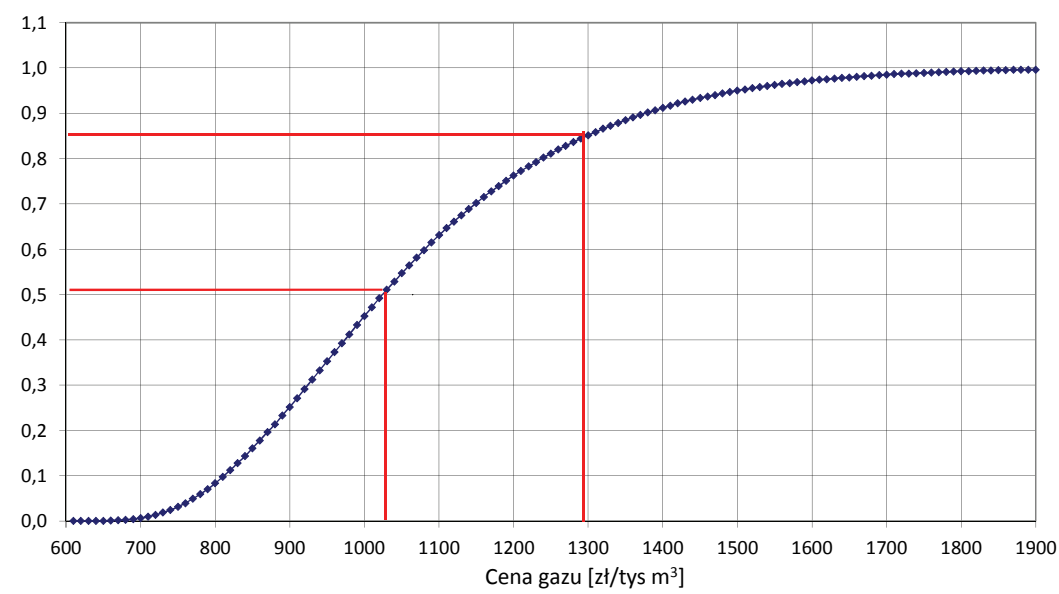

Rys. 1. Dystrybuanta rozkładu ceny gazu

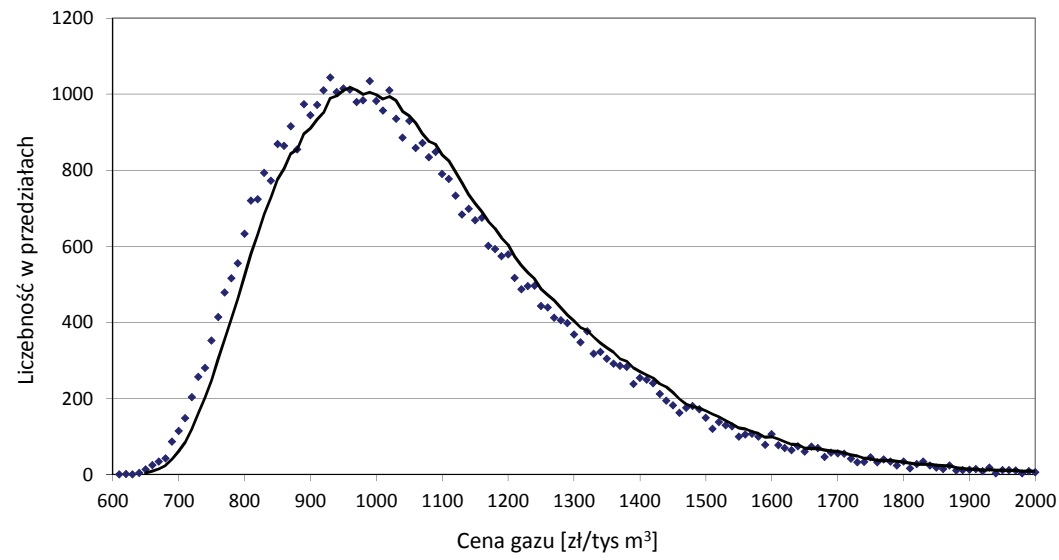

Rys. 2. Histogram eksperymentalny dla rozkładu ceny gazu - wariant A

5. W przypadku wariantu C2, w którym zwiększono nakłady inwestycyjne o 5500 tys. zł, zaobserwowano znaczący wzrost wartości: wyliczonej funkcji ryzyka do 26,4\% i najbardziej prawdopodobnej ceny gazu do $1090 \mathrm{zł} /$ tys. m³ .

\section{Wnioski}

1. Zaprezentowana publikacja jest jedną z propozycji definiowania i praktycznego wyliczania miary ryzyka inwestycji związanej z eksploatacją niekonwencjonalnych złóż gazu.
2. Ocena uzyskanych wartości zależy od poziomu akceptowalności (awersji) ryzyka inwestycji. Dla dużych inwestycji w sektorze energetycznym przyjmuje się, że akceptowalne ryzyko powinno być mniejsze niż 30\% [4]. Z tego 
punktu widzenia wyliczone wartości ryzyka dla wszystkich zaprezentowanych wariantów mieszczą się w przywołanej granicy.

3. Dodatkowym efektem, praktycznego zastosowania tej metody - oprócz oszacowania ryzyka inwestycji - jest wyznaczenie najbardziej prawdopodobnej ceny gazu, dla której inwestycja będzie opłacalna.

4. Zaproponowana metoda jest prosta $\mathrm{w}$ zastosowaniu i daje możliwość szybkiego sprawdzenia różnych scenariuszy zrealizowania inwestycji.

Prosimy cytować jako: Nafta-Gaz 2015, nr 5, s. 316-321, DOI: 10.18668/NG.2016.05.02

Artykuł nadesłano do Redakcji 10.11.2015 r. Zatwierdzono do druku 18.02.2016 r.

Artykuł powstał na podstawie pracy statutowej pt. Szacowanie ryzyka inwestycyjnego udostępnienia i eksploatacji niekonwencjonalnych złóż gazu - praca INiG - PIB na zlecenie MNiSW; nr zlecenia: 0029/KK/15/01, nr archiwalny: DK-4100-29/2015.

\section{Literatura}

[1] Ciechanowska M., Matyasik I., Such P., Kasza P., Lubaś J.: Uwarunkowania rozwoju wydobycia gazu z polskich formacji tupkowych. Nafta-Gaz 2013, nr 1, s. 7-17.

[2] Kelkar M.: Natural gas production engineering. ISBN 978-159370-017-1, Tulsa Oklahoma, pp. 228-253.

[3] Komisja Europejska, Dyrekcja Generalna ds. Polityki Regionalnej: Przewodnik do analizy kosztów i korzyści projektów inwestycyjnych - Raport końcowy. Materiały MRR, Warszawa 2008

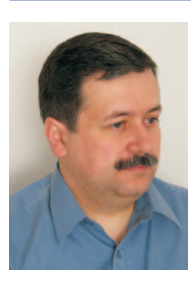

\section{Dr Tadeusz KWILOSZ}

Adiunkt w Zakładzie Podziemnego Magazynowania Gazu.

Instytut Nafty i Gazu - Państwowy Instytut Badawczy ul. Lubicz 25 A

31-503 Kraków

E-mail: tadeusz.kwilosz@inig.pl

[4] Paliński A.: Ocena ryzyka finansowego budowy podziemnego magazynu gazu z wykorzystaniem symulacji Monte Carlo. Międzynarodowa Konferencja Naukowo-Techniczna GEOPETROL 2008, Zakopane-Krościenko 15-18.09.2008, Prace Instytutu Nafty i Gazu 2008, nr 150, s. 1045-1050.

[5] Salman A. Mengal, Wattenbarger R. A.: Accounting For Adsorbed Gas in Shale Reservoirs. SPE Paper no. 41085, s. 643-658.

[6] Szott W., Gołąbek A.: Symulacje procesu eksploatacji złóż gazu ziemnego w formacjach łupkowych (shale gas). Nafta-Gaz 2012, nr 12, s. 923-936.

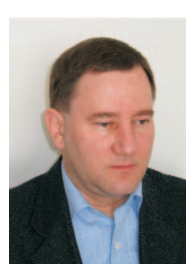

Mgr inż. Bogdan FILAR

Starszy specjalista badawczo-techniczny; kierownik Zakładu Podziemnego Magazynowania Gazu.

Instytut Nafty i Gazu - Państwowy Instytut Badawczy ul. Lubicz 25 A

31-503 Kraków

E-mail:bogdan.filar@inig.pl

\section{OFERTA}

\section{ZAKŁAD PODZIEMNEGO MAGAZYNOWANIA GAZU}

Zakres działania:

- $\quad$ analiza struktur geologicznych złóż gazu ziemnego, ropy naftowej oraz obiektów zawodnionych, pod kątem możliwości ich przekształcenia w PMG;

- $\quad$ szczegółowa analiza warunków geologiczno-złożowych, ocena dotychczasowej eksploatacji złoża, warunków hydrodynamicznych, zdolności wydobywczych odwiertów;

- $\quad$ ocena stanu technicznego istniejącej infrastruktury w aspekcie jej wykorzystania w pracy PMG;

- $\quad$ wykonywanie cyfrowych modeli geologicznych PMG, złóż gazu ziemnego i ropy naftowej;

- wykonanie projektu budowy PMG;

- $\quad$ analiza dotychczasowej pracy istniejących PMG w celu optymalizacji parametrów dalszej eksploatacji magazynów na bazie symulacji komputerowej;

- opracowanie projektów prac geologicznych, dotyczących poszukiwania i rozpoznawania złóż gazu ziemnego i ropy naftowej;

- opracowanie dokumentacji geologicznych złóż ropy naftowej i gazu ziemnego;

- opracowanie programu optymalnej eksploatacji złoża, wydajności poszczególnych odwiertów, tempa sczerpywania itp. 